\title{
NOTES ON TACHINID PARASITES OF CHRYSOMELIDAE.
}

\author{
BY FREDERICK KNAB, WASHINGTON, D. C.
}

DURING the past summer the writer repeatedly visited some clumps of willows at the head of Plummer's Island, Maryland, in order to observe the habits of Calligrapha bigsbyana. On August 16 the following scene between a tachinid fly and a Calligrapha was observed among these willows. Upon the upper surface of a willow leaf, near its base, a specimen of Calligrapha was found, and in front, facing it, a rather small tachinid fly. The beetle was in the attitude of attention, its antennae held obliquely forward, while the fly sat facing it, just out of reach. The beetle appeared to be on the defensive and both insects remained motionless for several minutes. Finally the beetle advanced, and as it did so the fly retired, walking rapidly backward and all the time facing the beetle. Soon the fly reached the tip of the leaf and as the beetle bore down upon it the fly quickly transferred itself to the nearest leaf, whence it continously watched the movements of the beetle. The beetle advanced to the tip of the leaf, immediately turned around and started back again. As soon as there was room the fly returned to the leaf and followed close behind the beetle, at times even touching it. The pair proceeded back over the leaf to the stem and down the branch of the willow some nine or ten inches, the beetle winding about among the bracts, leaves and twigs, the fly always keeping close, either directly behind or directly opposite on the branch. When the beetle turned and came back over the same route the fly still followed close behind, the pair finally going out upon another leaf and from this to another one that was in contact. From this leaf the route again went to the branch and the rapid course then led farther into the bush where it was difficult to follow the movements of the pair. Fearful of losing the interesting fly I captured it, together with the beetle. 'The fly's behavior suggested a contemplated attempt at oviposition. However no eggs could be found upon the beetle.

The tachinid was sent to Mr. C. H. T. Townsend for identification. He replied that "the species is probably to be referred to Anisia, and is related to Hypostena barbata Cogt., which has been bred from an adult beetle of Disomycha xanthomelaena collected near Washington, D. C." Mr. Townsend further stated that the specimen was opened "and disclosed uterine maggots of a type different from any that we have so far seen." It is evident, therefore, that this tachinid deposits living larvae; whether upon the beetle itself (as the actions of the fly would indicate) or upon its larvae remains to be determined. 
It has long been known that tachinid flies parasitise adult beetles. It appears that not all of them have the same mode of infesting their host. Thus on June 14 I took a female Lina scripta which had four eggs of a tachinid fastened upon her elytra. This beetle was kept alive in order to ascertain if the parasitism was successful. Shortly afterward this beetle laid a large number of eggs and in the course of another week died. No tachinids resulted although the dead beetle was kept in the breeding jar for several weeks.

A number of records have been made of tachinid rearings from adult Chrysomelidae, as well as from coleoptera of other families. It is doubtful, however, that any statements can be found that indicate the mode of parasitization or the habits of the tachinids in question. It is to be hoped that this subject, in which Townsend has recently opened such an interesting perspective, will attract other students.

\title{
A LIST OF COLEOPTERA COLLECTED WITHIN TEN MILES OF FALL RIVER, MASSACHUSETTS.
}

\author{
BY NORMAN S. EASTON, FALL RIVER, MASS.
}

ONE of the aims of the Fall River Society of Natural History is to make a list of the fauna and flora found within ten miles of the City Hall. All the beetles in the following list were taken within this ten mile radius, and with a few exceptions, are represented in the collection of the society. Fully ninety percent have been taken during the last five years by a single individual. At least three hundred more species may be confidently expected to occur in the region.

The region, coming as it does, within a debatable portion of the transitional zone, is a very interesting one. The varied physical features make it a delightful and productive collecting ground.

From North to South, directly through the center of the region, runs the escarpment formed on account of the contact between hard granitic rocks and the soft sediments of the Rhode Island coal measures. A mile or more to the eastward of this contact, upon the upland, lies a chain of fresh water lakes, extending nearly the length of the area. To the eastward of the lakes are tracts of forest growth, principally of oak and pine, and extended areas of dense cedar swamps.

To the westward, of the escarpment lies the estuarian region of the Narragansett basin, with its miles of varied shore lines and acres of cleared lands. 

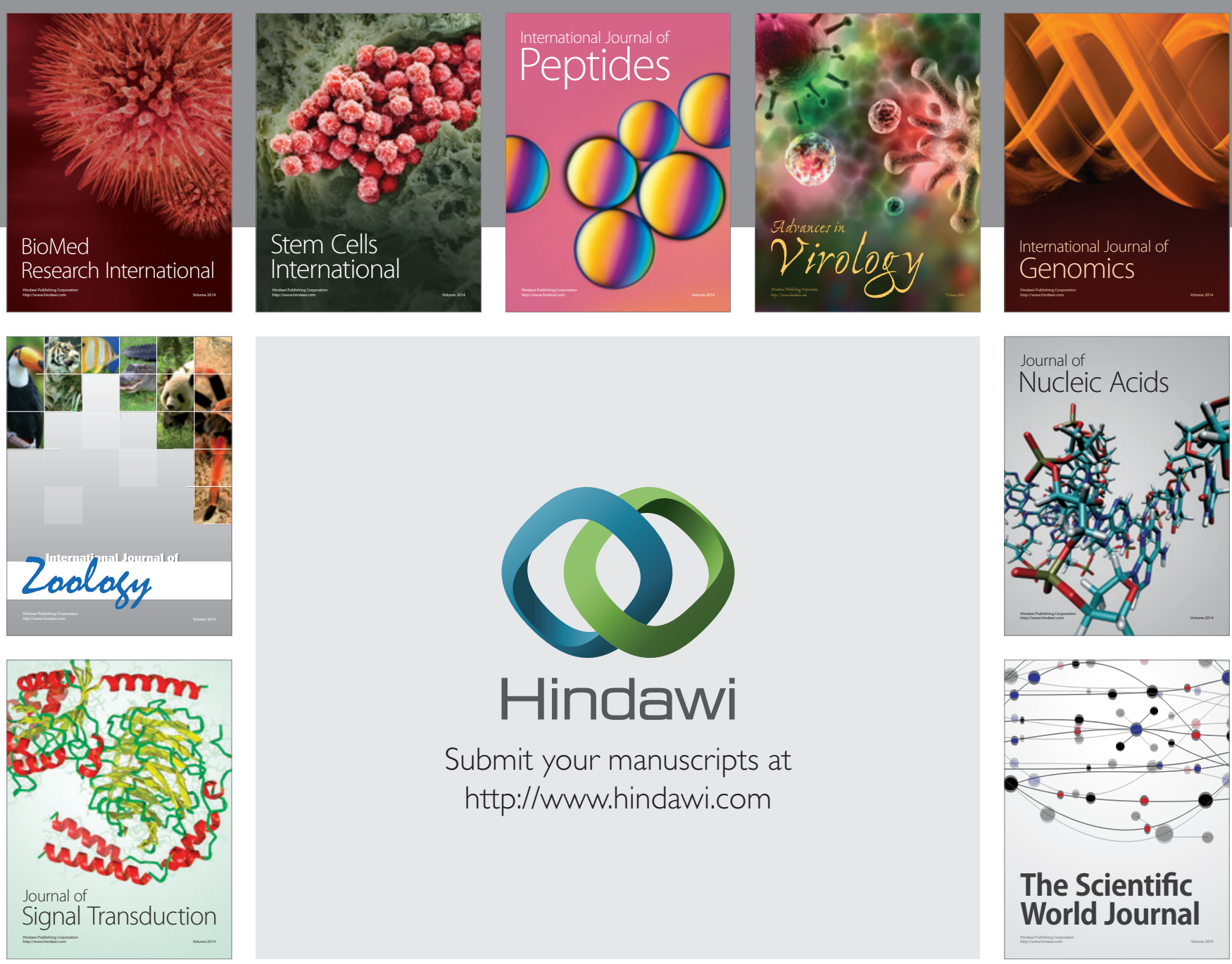

Submit your manuscripts at

http://www.hindawi.com
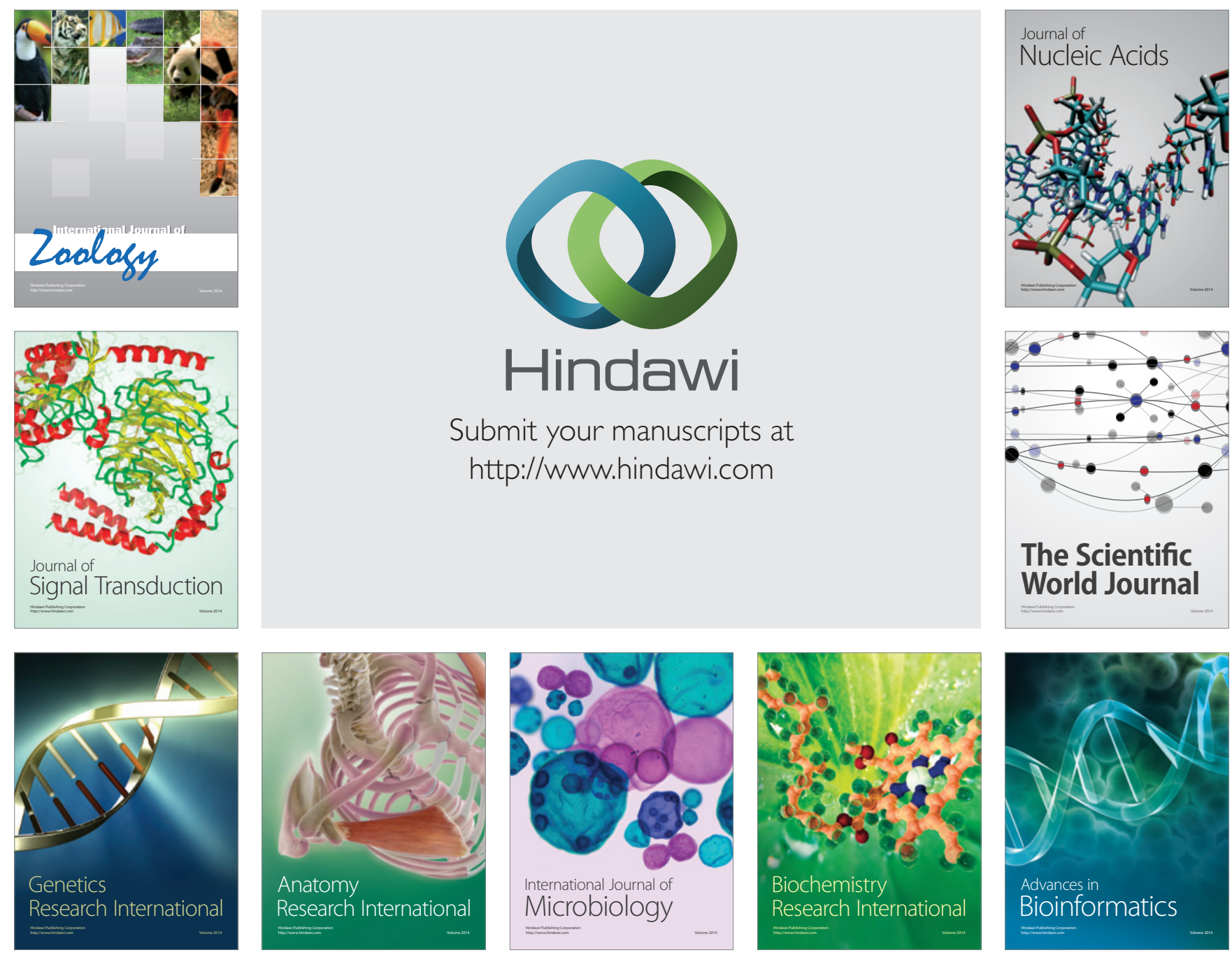

The Scientific World Journal
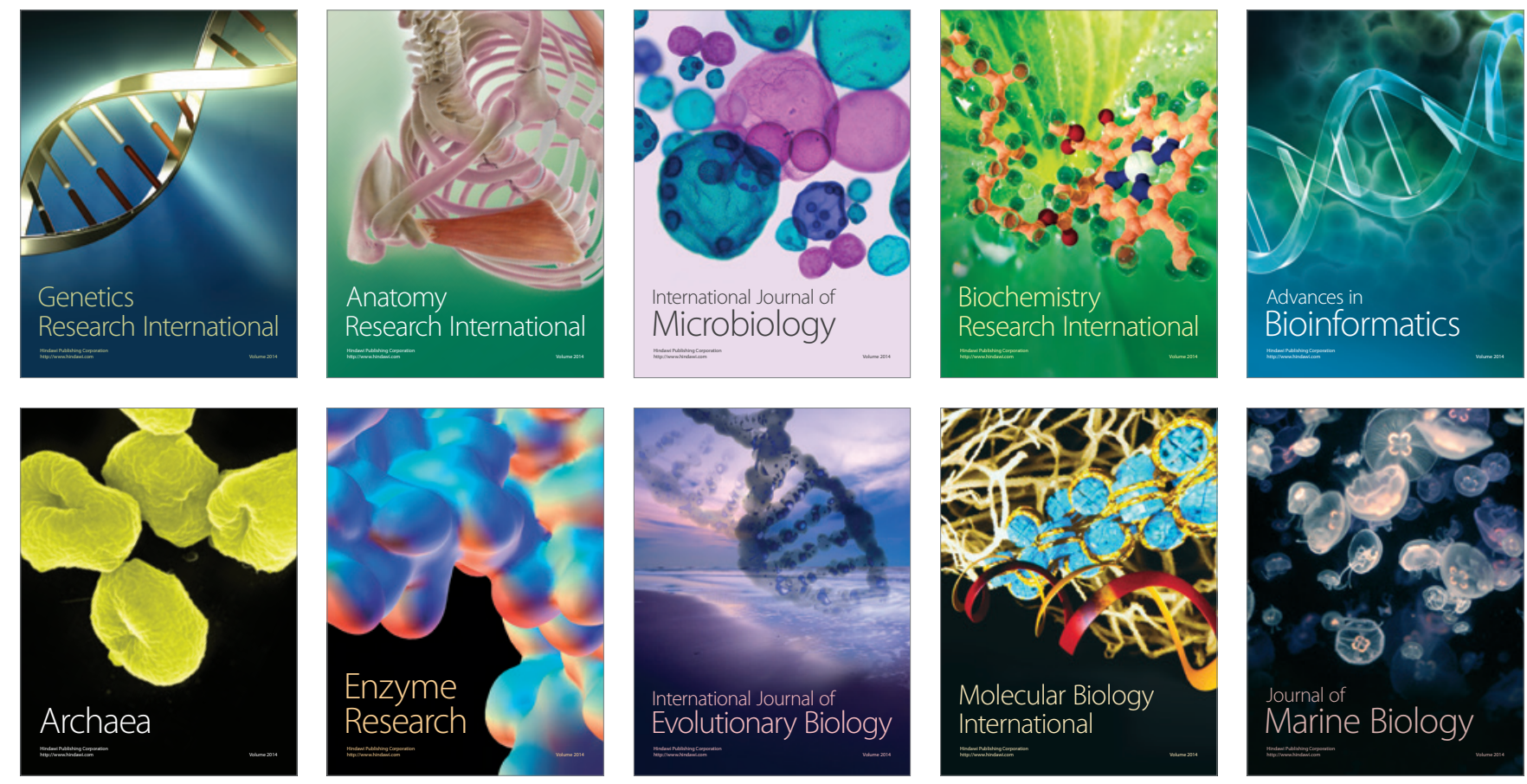